\title{
Low-dose radiation exposure induces a HIF-1-mediated adaptive and protective metabolic response
}

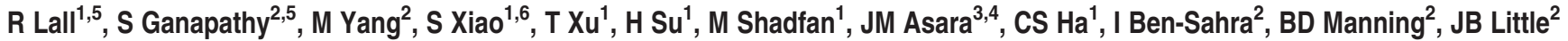 \\ and Z-M Yuan ${ }^{\star 2}$
}

Because of insufficient understanding of the molecular effects of low levels of radiation exposure, there is a great uncertainty regarding its health risks. We report here that treatment of normal human cells with low-dose radiation induces a metabolic shift from oxidative phosphorylation to aerobic glycolysis resulting in increased radiation resistance. This metabolic change is highlighted by upregulation of genes encoding glucose transporters and enzymes of glycolysis and the oxidative pentose phosphate pathway, concomitant with downregulation of mitochondrial genes, with corresponding changes in metabolic flux through these pathways. Mechanistically, the metabolic reprogramming depends on HIF1 $\alpha$, which is induced specifically by lowdose irradiation linking the metabolic pathway with cellular radiation dose response. Increased glucose flux and radiation resistance from low-dose irradiation are also observed systemically in mice. This highly sensitive metabolic response to lowdose radiation has important implications in understanding and assessing the health risks of radiation exposure.

Cell Death and Differentiation (2014) 21, 836-844; doi:10.1038/cdd.2014.24; published online 28 February 2014

The advance of diagnostic imaging and interventional radiology has attracted growing interest in the biological effects of low-dose ( $\leqslant 0.1 \mathrm{~Gy}$ ) ionizing radiation (IR). ${ }^{1}$ Because of a lack of means for the direct assessment of such low-dose IR exposure, however, there are great uncertainties about its health risk. ${ }^{1}$ Currently, a linear no-threshold (LNT) dose model is used to predict low-dose IR-induced biological effects, ${ }^{2}$ which assumes that the underlying biological processes induced by low-dose IR are essentially the same as those triggered by higher-dose IR, and thus extrapolates the effects from high-dose to low-dose radiation. ${ }^{3}$ Based on this model, any amount of radiation could cause harm no matter how small the dose. Studies have shown, however, the existence of adaptive doseresponse relationships with low doses being protective and high doses causing detrimental effects, contradicting the LNT model. ${ }^{4,5}$ This adaptive response is in fact part of a general cellular response to stress that is evolutionally conserved. ${ }^{6}$ Hence, many have argued that the use of the LNT model has led to unfounded levels of public fear regarding low levels of radiation exposure, and misunderstandings about the safety of diagnostic imaging for medical use. ${ }^{1}$ However, the controversy remains unresolved due to a lack of understanding of the molecular mechanisms underlying the adaptive stress response, ${ }^{7,8}$ and there is insufficient scientific evidence to warrant a change from the LNT model.
Biological tissues consist of $\sim 75 \%$ water by weight. A major fraction of IR exposure induces hydrolysis resulting in different types of reactive oxygen species (ROS). ${ }^{9}$ IR induces the production of ROS proportional to its dose. High-dose IR induces an excess amount of ROS that can overwhelm the cellular antioxidant capacity causing oxidative stress and damages. ${ }^{9}$ When mildly increased, ROS, however, can function as signal molecules modulating cellular physiology. ${ }^{10,11}$ ROS act through oxidation of reactive cysteine residues in specific target proteins controlling various signaling cascades. A prototype of the ROS-susceptible proteins is phosphatases. ${ }^{12,13}$ The hypoxia-inducible factor 1 (HIF-1), a master transcription factor that controls cellular metabolism, is markedly induced by hypoxia. ${ }^{14,15}$ Under certain normoxic conditions, however, HIF-1 $\alpha$ expression can also be increased. For instance, the $\mathrm{NF}_{\kappa} \mathrm{B}$ pathway stimulates transcription of $H I F-1 \alpha,{ }^{16,17}$ the PI3K/AKT/mTOR pathway promotes HIF- $1 \alpha$ mRNA translation ${ }^{18}$ and ROS inhibits HIF- $1 \alpha$ degradation. ${ }^{10}$ Upon induction, HIF-1 $\alpha$ stimulates transcription of genes encoding glucose transporters and enzymes of glycolysis and the pentose phosphate pathway (PPP). ${ }^{19,20}$ HIF-1 $\alpha$ also negatively regulates TCA cycle enzymes, indirectly through inducing miR120.21,22

In this report, we describe a previously unrecognized metabolic response to low-dose radiation. By using an integrated approach, we demonstrate that low-dose radiation

\footnotetext{
${ }^{1}$ University of Texas Health Science Center, San Antonio, TX, USA; ${ }^{2}$ Department of Genetics and Complex Diseases, Harvard University School of Public Health, Boston, MA, USA; ${ }^{3}$ Division of Signal Transduction, Beth Israel Deaconess Medical Center, Boston, MA, USA and ${ }^{4}$ Department of Medicine, Harvard Medical School, Boston, MA, USA

${ }^{*}$ Corresponding author: Z-M Yuan, Department of Genetics and Complex Diseases, Harvard University School of Public Health, Building 1, Room 509, 665 Huntington Avenue, Boston, MA, USA. Tel: +1 617432 2139; Fax: +1 617432 2296; E-mail: zyuan@ @sph.harvard.edu

${ }^{5}$ These authors contributed equally to the study.

${ }^{6}$ Current address; Beijing University Cancer Hospital, Beijing 100142, China.

Abbreviations: CT, computed tomography; ECAR, elevated extracellular acidification rate; 2-DG, 2-deoxyglucose; G6PD, glucose-6-phosphate dehydrogenase; GLUT, glucose transporter; HIF-1, hypoxia induced factor; IR, ionizing radiation; LDH, lactate dehydrogenase; LNT, linear no-threshold; LD50, lethal dose of 50\%; MCT, monocarboxylate transporter; PPP, pentose phosphate pathway; ROS, reactive oxygen species; SOD, superoxide dismutase; TCA, tricarboxylic acid cycle Received 14.11.13; revised 20.1.14; accepted 22.1.14; Edited by N Chandel; published online 28.2.14
} 
induces a metabolic shift from oxidative phosphorylation to aerobic glycolysis leading to increased radiation resistance in both cell and animal models. Low-dose radiation-induced metabolic changes are mediated by HIF-1 $\alpha$. Our work provides novel mechanistic insights into the low-dose radiation-induced adaptive response.

\section{Results}

Radioadaptive response is sensitive to oxygen concentration. Since the direct biological consequences of low-dose irradiation are relatively subtle and difficult to measure, ${ }^{7,8}$ we opted to study the radioadaptive response model to investigate the effects of low-dose radiation because animal studies have demonstrated such adaptive response. ${ }^{6}$ We define doses at or below $0.1 \mathrm{~Gy}$ as low-dose radiation, ${ }^{7}$ equivalent to the upper limit dose from a full-body spiral CT $\operatorname{scan}^{8}$ and 2-4Gy as high-dose radiation that causes substantial DNA damage to cells, ${ }^{9,23} 4 \mathrm{~Gy}$ is close to the LD50 for human whole-body exposure. ${ }^{24}$ Using $\gamma \mathrm{H} 2 \mathrm{AX}$ as a surrogate marker of DNA damage, ${ }^{23}$ we examined whether 0.1 Gy pretreatment of human fibroblasts could modulate cell sensitivity to a subsequent $4 \mathrm{~Gy}$ irradiation. Unexpectedly, despite repeated attempts, we failed to detect any adaptive response. 4Gy irradiation induced comparable extents of $\gamma \mathrm{H} 2 \mathrm{AX}$ in cells with or without $0.1 \mathrm{~Gy}$ pretreatment (Figures $1 \mathrm{a}$ and $\mathrm{b}$ ). Human lymphocytes, which are very sensitive to IR-induced apoptosis, ${ }^{23}$ also did not show differences in $4 \mathrm{~Gy}$-induced apoptosis regardless of cells pre-exposed to $0.1 \mathrm{~Gy}$ irradiation or not (Supplementary Figure 1A). The inability to reproduce the radioadaptive response seen previously in mice prompted us to ask whether the superphysiological oxygen concentration (20-21\% $\left.\mathrm{O}_{2}\right)$ under typical tissue culture conditions might mask the effects of

a
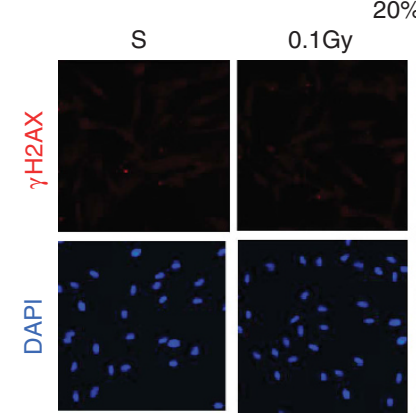

e
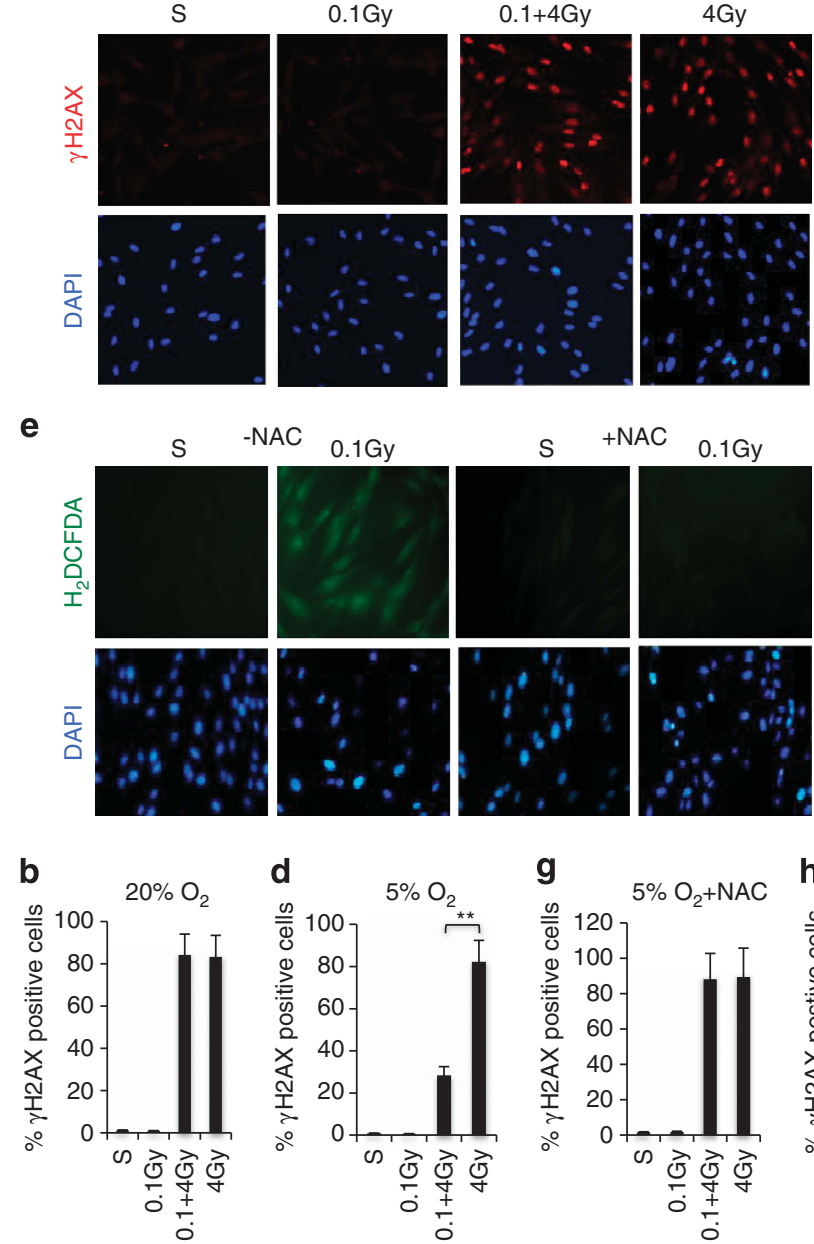

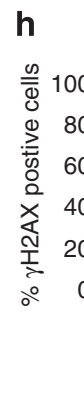

C
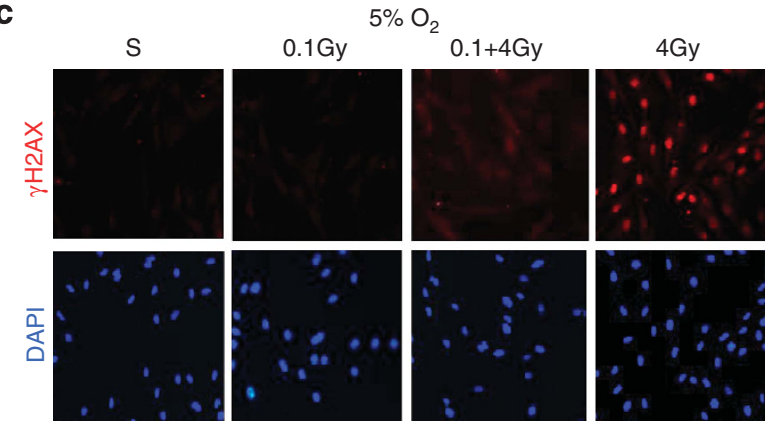

f
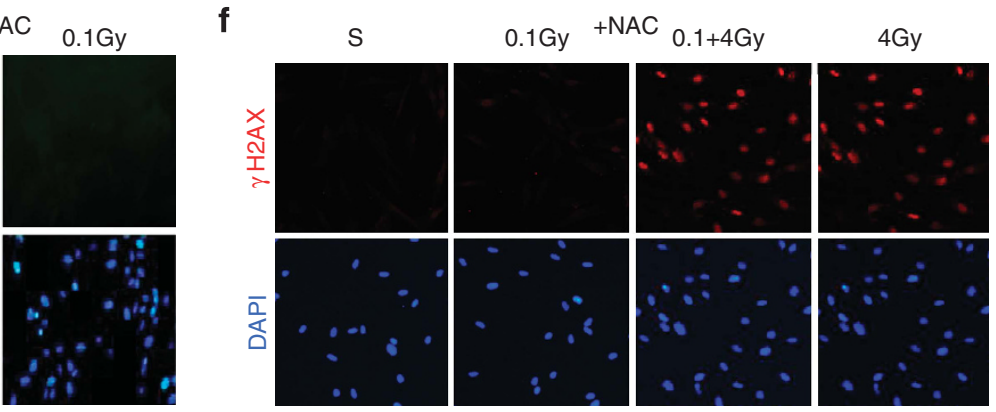

Solvent $\quad 0.1 \mathrm{mM} \quad 0.25 \mathrm{mM} \quad 0.5 \mathrm{mM} \quad 0.75 \mathrm{mM} \quad 1.0 \mathrm{mM} \quad 10 \mathrm{mM}$ (NAC)

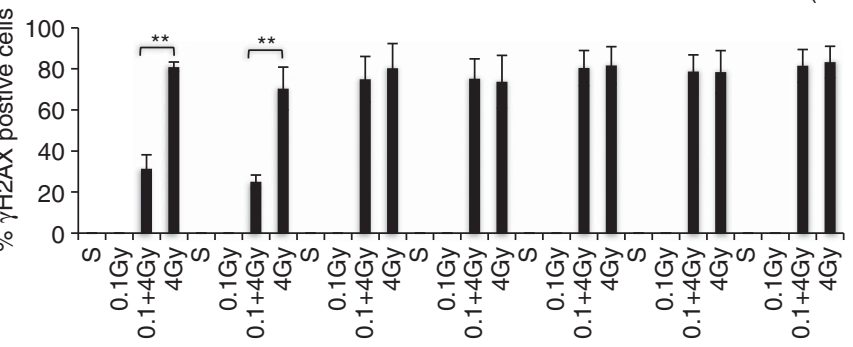

Figure 1 Cellular radioadaptive response is very sensitive to environmental oxygen concentration. (a) Human fibroblasts were cultured under conventional condition $\left(20-21 \% \mathrm{O}_{2}\right)$. For assessing the effect of $0.1 \mathrm{~Gy}$ on $4.0 \mathrm{~Gy}$-induced DNA damage, cells were pretreated with a dose of $0.1 \mathrm{~Gy}$ or sham treated, after $12 \mathrm{~h}$, followed by a 0 or $4.0 \mathrm{~Gy}$ treatment. The cells were harvested $1 \mathrm{~h}$ after the 4 Gy treatment and subjected to immunostaining with $\gamma \mathrm{H} 2 \mathrm{AX}$ (red) and DAPI (blue). (b) Quantification of $\gamma \mathrm{H} 2 \mathrm{AX}$-positive cells shown in a. Bars represent mean \pm S.D. of ( 100 cells per sample) three independent experiments. ${ }^{*}<0.05,{ }^{* *}<0.01$. (c). Human fibroblasts were maintained at $5 \% \mathrm{O}_{2}$ for at least $12 \mathrm{~h}$ before being irradiated and analyzed as described in a. (d) Quantitative analysis of $\gamma \mathrm{H} 2 \mathrm{AX}$-positive cells shown in $\mathbf{c}$ was carried out as in $\mathbf{b}$. (e) Human fibroblasts were pretreated with or without $10 \mathrm{mM} \mathrm{NAC}$ for $1 \mathrm{~h}$. The cells were either sham or $0.1 \mathrm{~Gy}$ irradiated and harvested $1 \mathrm{~h}$ after for immunostaining with carboxy-H2DCFDA (\#C400, Invitrogen/Molecular probes, green) and DAPI (blue). ( $f$ ) Fibroblasts were treated with $10 \mathrm{mM} \mathrm{NAC}(+\mathrm{NAC})$ for $1 \mathrm{~h}$ and then subjected to the treatment and analysis as in $\mathbf{a}$. (g) Quantitative analysis of $\gamma \mathrm{H} 2 \mathrm{AX}$-positive cells shown in $\mathbf{f}$ was carried out as in $\mathbf{b}$ 
low-dose IR. Indeed, cell cultures maintained at a relatively physiological oxygen concentration $\left(5 \% \mathrm{O}_{2}\right)^{25}$ recapitulated the cellular radioadaptive response, as reflected by that 0.1 Gy pretreatment markedly diminished $\gamma \mathrm{H} 2 \mathrm{AX}$ induced by subsequent 4 Gy exposure (Figure 1c). Quantitative analysis of the $\gamma \mathrm{H} 2 \mathrm{AX}$-positive cells indicated a very significant increase of resistance induced by $0.1 \mathrm{~Gy}$ irradiation (Figure 1d). Similarly, 0.1 Gy pretreatment of human lymphocytes also markedly attenuated 4 Gy-induced apoptosis under physiological oxygen concentrations (Supplementary Figure 1B). This observed sensitivity to oxygen concentration suggests an involvement of ROS. We tested this prediction with $\mathrm{N}$-acetyl-cysteine (NAC), a commonly used antioxidant. Using a ROS-sensitive fluorescent probe, $\mathrm{H}_{2}$ DCFDA, we confirmed ROS induction by $0.1 \mathrm{~Gy}$ irradiation, which was blocked by NAC (Figure 1e). Importantly, NAC also blocked $0.1 \mathrm{~Gy}$ induced reduction of $\gamma \mathrm{H} 2 \mathrm{AX}$ in $4 \mathrm{~Gy}$-treated cells (Figures 1f and $\mathrm{g}$ ). The requirement for ROS in the radioadaptive response was also seen with human lymphocytes (Supplementary Figure 1C). A dose course experiment of NAC was curried out to eliminate a potential off-target effect. The result indicates that $0.25 \mathrm{mM}$ of NAC was adequate to block 0.1 Gy-induced resistance (Figure $1 \mathrm{~h}$ ). Moreover, cells overexpressing superoxide dismutase (SOD) were defective in the radioadaptive response (Supplementary Figure 1D), indicative of the necessity of ROS. Interestingly, pretreatment of fibroblasts with 0.1 Gy-IR also reduced bleomycin-induced DNA damage (Supplementary Figure 1E), implicating that low-dose IR-induced resistance is not limited to radiation-induced damage. Together, the results indicate that pretreatment with low-dose IR increases cellular radiation resistance via inducing ROS, and such radioadaptive response is very sensitive to the environmental oxygen concentration. Therefore, all subsequent experiments are performed under physiological oxygen concentrations.

Low-dose radiation induces a metabolic shift to glycolysis. Following exposure to low-dose radiation, a marked acidification of the culture media was observed within $12 \mathrm{~h}$, as indicated by color change (Supplementary Figure 2A). We asked whether this color change was caused by altered cellular metabolism by measuring metabolites in media. Indeed, 0.1Gy-treated cells secreted more lactate than controls and this effect was specific to low-dose IR, as 4 Gy treatment did not induce lactate production (Figure 2a). We examined the expression of monocarboxylate transporters (MCT), which transport lactate across membranes ${ }^{26}$ and found that among $7 \mathrm{MCTs}$, the MCT1 transcript was significantly induced by $0.1 \mathrm{~Gy}$ treatment (Figure $2 \mathrm{~b}$ ). As lactate can be produced as the end product of glycolysis, ${ }^{19,20}$ we measured glucose levels and detected an increase in glucose consumption induced by $0.1 \mathrm{~Gy}$ but not $4 \mathrm{~Gy}$ irradiation (Figure 2c). Together with an elevated extracellular acidification rate (ECAR) in 0.1 Gy-treated cells, measured with a Seahorse XF Analyzer (Figure 2d), the results suggest an induction of glycolysis specific to low-dose IR.

To further characterize the metabolic changes induced by low-dose radiation, we performed a stable isotope metabolic flux analysis using $\left[1,2-{ }^{13} \mathrm{C}\right]$-glucose. ${ }^{27,28} \mathrm{An}$ increase in
${ }^{13} \mathrm{C}$-labeled glycolytic intermediates in $0.1 \mathrm{~Gy}$ irradiated cells was detected (Figure 2e), accompanied by a decrease in labeling of TCA cycle intermediates (Figure 2f), suggesting a metabolic switch from oxidative phosphorylation to glycolysis. In addition, increased labeling of 6-phospho-D-gluconate, a metabolite specific to the oxidative PPP, was detected following $0.1 \mathrm{~Gy}$ irradiation (Figure $2 \mathrm{~g}$ ). To substantiate the metabolomics results, we measured the expression of key enzymes in these metabolic pathways. Indeed, $0.1 \mathrm{~Gy}$ treatment induced a number of glycolytic enzymes and glucose-6-phosphate dehydrogenase (G6PD), the rate-limiting enzyme in the oxidative PPP, which was coupled with downregulated expression of TCA cycle enzymes (Figure 2h). Increased levels of these metabolic enzymes upon $0.1 \mathrm{~Gy}$ treatment were also observed at the protein level (Figure 2i). Moreover, 0.1 Gy treatment of human fibroblasts also induced an increase in GLUT-1 and GLUT-3 at both the mRNA (Figure 2j) and the protein levels (Figure 2k), consistent with increased glucose flux. ${ }^{20}$

The glycolytic switch is necessary for low-dose IRinduced resistance. The low-dose IR-induced glycolytic shift under normoxic conditions is similar to the 'Warburg effect', which has been shown to have an important role in promoting cancer cell proliferation and survival. ${ }^{19}$ We asked whether the glycolytic shift might contribute to the low-dose IR-induced radiation resistance. Interestingly, the 0.1 Gy-induced radiation resistance detected in normal culture medium (25 mM glucose) (Figure 3a) was nearly abolished when glucose levels were reduced to $2 \mathrm{mM}$ (Figure $3 \mathrm{~b}$ ) or cells were treated with 2-deoxyglucose (2-DG), a glucose analog that inhibits glycolysis and the PPP ${ }^{19}$ (Figure $3 \mathrm{c}$ ). The importance of glucose uptake and glycolysis in low-dose radiation-induced resistance was also observed in human lymphocytes (Supplementary Figure 2B-D). siRNA-mediated knockdown of $\mathrm{LDH} \alpha$, an enzyme critical to maintaining glycolytic flux ${ }^{29}$ had a similar effect to that of 2-DG on the level of $\gamma \mathrm{H} 2 \mathrm{AX}$ induction (Figure $3 \mathrm{~d}$ ), further demonstrating that the $0.1 \mathrm{~Gy}$-induced radiation resistance depends on the glycolytic shift. Knockdown of G6PD expression similarly resulted in loss of $0.1 \mathrm{~Gy}$-induced resistance (Figure $3 e$ ), indicating that the oxidative PPP is also indispensable. A critical contribution of these two metabolic enzymes to lowdose IR-induced resistance was also evident in cell survival assays. In contrast to the control siRNA (Figure 3f), $0.1 \mathrm{~Gy}$ induced resistance was diminished in cells deficient in $\mathrm{LDH} \alpha$ (Figure $3 \mathrm{~g}$ ) or G6PD (Figure 3h). Together, these data indicate that the $0.1 \mathrm{~Gy}$-induced increase in flux through glycolysis and the oxidative PPP induces radiation resistance.

HIF-1 $\alpha$ mediates the metabolic switch upon exposure to low-dose IR. Given that multiple metabolic enzymes were induced by $0.1 \mathrm{~Gy}$ treatment (Figure 2) and many of these metabolic genes are the known targets of $\mathrm{HIF} 1 \alpha,{ }^{14,15}$ we explored a potential role for this transcription factor. Immunostaining and immunoblotting analyses indicated that 0.1 Gy treatment induced a considerable increase in HIF $1 \alpha$ protein levels (Figures $4 \mathrm{a}$ and b), without effects on its transcript levels (Figure 4c), indicating a post-transcriptional 


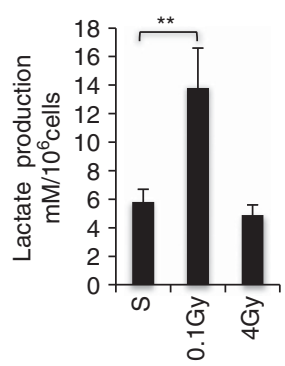

b

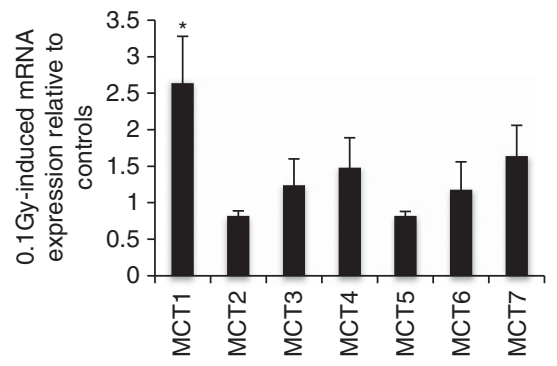

C

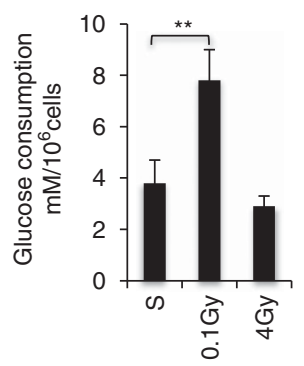

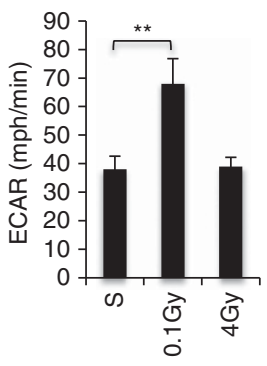

e

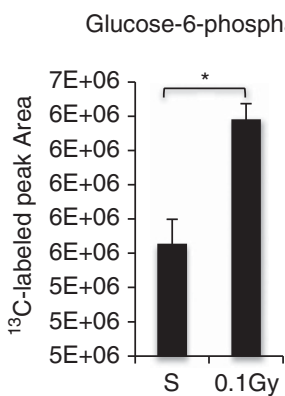

The glycolytic metabolites

Glyceraldehyde-3phosphate f

The TCA cycle metabolites

Dihydroxy-acetonephosphate
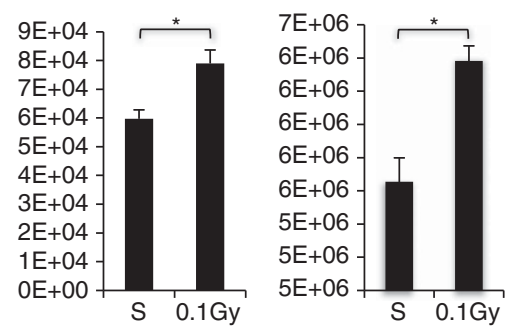

Fumarate

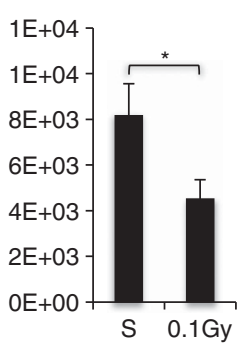

Succinate

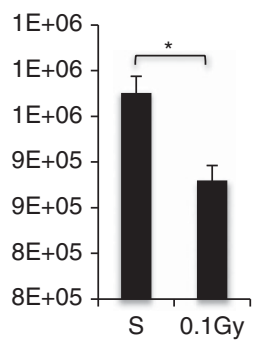

g The PPP metabolite

6-phospho-Dgluconate

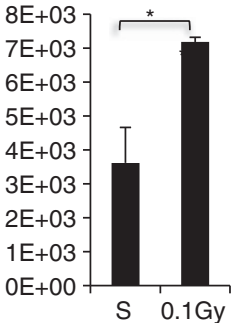

h

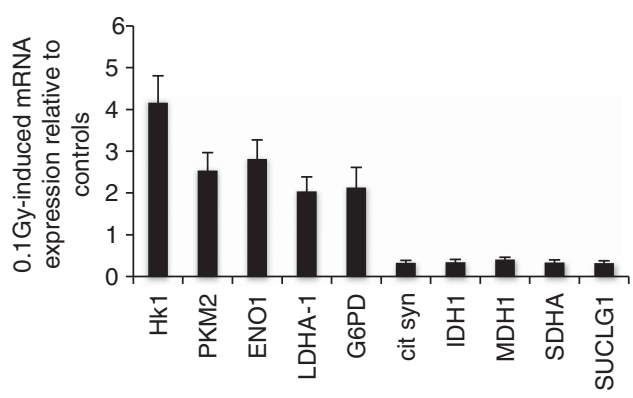

i

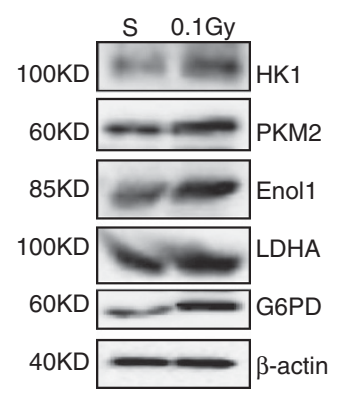

j

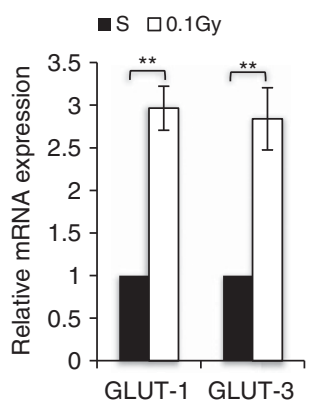

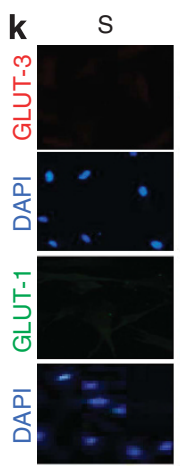

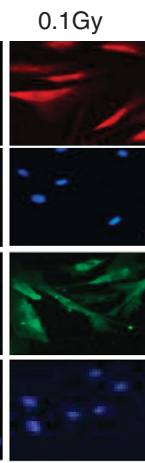

Figure 2 Low-dose radiation induces a metabolic shift. Human fibroblasts were either sham treated (S) or irradiated at $0.1 \mathrm{~Gy}$ and $12 \mathrm{~h}$ after the treatment; (a) culture media from an equal number of fibroblasts $\left(1 \times 10^{6}\right)$ were collected for lactate measurement. The numbers are mean \pm S.D. from three independent experiments. ${ }^{*}<0.05$, ${ }^{* *}<0.01$. (b) An aliquot of cells were harvested and mRNA were isolated for qRT-PCR analysis of MCT expression with $18 \mathrm{~s}$ as an internal standard. The numbers are fold change of MCT mRNA levels in 0.1 Gy relative to sham-treated cells as mean \pm S.D. from three independent experiments. (c) Glucose consumption was determined in cells as in a and the numbers are mean \pm S.D. from three independent experiments. (d) Fibroblasts were treated as in a and subjected to analysis using the XF Analyzer according to the manufacture's protocol (Seahorse Bioscience). The numbers are mean \pm S.D. from three independent experiments. (e-g). Fibroblasts treated as in a and the cells were incubated with $\left[1,2-{ }^{13} \mathrm{C}\right]$-glucose for $15 \mathrm{~min}$ prior to metabolite extraction and targeted LC-MS/MS analysis. The ratio of ${ }^{13} \mathrm{C}$ labeled to unlabeled $\left({ }^{12} \mathrm{C}\right)$ metabolites was measured by LC-MS/MS are presented as mean \pm S.D. over three independent samples, ${ }^{*}<0.05,{ }^{* \star}<0.01$. Metabolites with $P$-values for pair-wise comparisons $<0.05$ are shown. (h) mRNAs as in b were analyzed with qRT-PCR for the expression of the indicated genes. The numbers are mean \pm S.D. from three independent experiments. (i) Cell lysates were analyzed by western blot with the indicated antibody. Human fibroblasts treated as in a were harvested $12 \mathrm{~h}$ after the treatment and analyzed by either qRT-PCR (j) or immunostaining (k) of GLUT-1 or 3

mechanism of regulation. To access the effectiveness of $0.1 \mathrm{~Gy}$-IR in HIF $1 \alpha$ induction, we compared low-dose irradiation with hypoxia $\left(0.5 \% \mathrm{O}_{2}\right)$. Relative to hypoxia, $0.1 \mathrm{~Gy}$ IR induced a comparable, if not more, increase in HIF1 $\alpha$ and its target gene GLUT-3 (Supplementary Figure 3). To understand the mechanism of this induction, we explored a role for ROS, which have been shown to stabilize $\operatorname{HIF} 1 \alpha .^{10,18}$ Treatment of cells with NAC confirmed a critical role for ROS, as this antioxidant completely blocked 0.1 Gy-induced increase of $\mathrm{HIF} 1 \alpha$ (Figure $4 \mathrm{~d}$ ). A requirement of $\mathrm{HIF} 1 \alpha$ in $0.1 \mathrm{~Gy}$-induced expression of glycolytic genes (Figure $4 \mathrm{e}$ ), and GLUT-1 and 3 (Figure 4f) was demonstrated by HIF1 $\alpha$ knockdown. Interestingly, the expression of TCA cycle genes was no longer downregulated by 0.1 Gy treatment upon HIF1 $\alpha$ depletion (Figure 4e). Furthermore, HIF1 $\alpha$-depleted cells lost the radioadaptive response, as shown in cell survival assay (Figure $4 \mathrm{~g}$ ), indicating that HIF1 $\alpha$ is necessary for low-dose IR-induced resistance.

Having observed that IR-induced glycolysis was specific to low-dose treatment, (Figures 2 and 3) we examined whether $\mathrm{HIF} 1 \alpha$ responded to IR in a dose-dependent manner by performing a detailed radiation dose course experiment. We included p53 as a control because it is readily activated by IR-induced DNA damage. ${ }^{30-32}$ By monitoring the expression of p21 and GLUT-3, as markers for p53 and HIF1 $\alpha$ activity, respectively, we detected a clear dose-dependent response. 
a

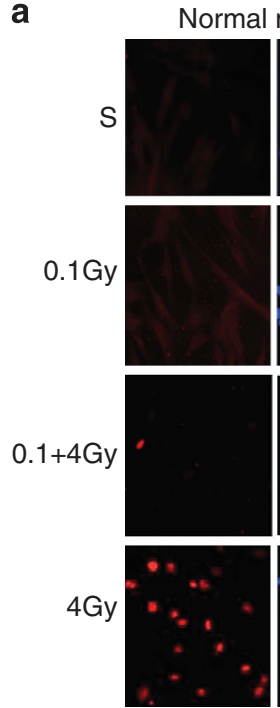

$\gamma \mathrm{H} 2 \mathrm{AX}$
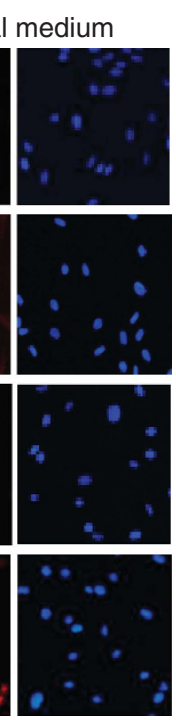

DAPI b Low glucose medium
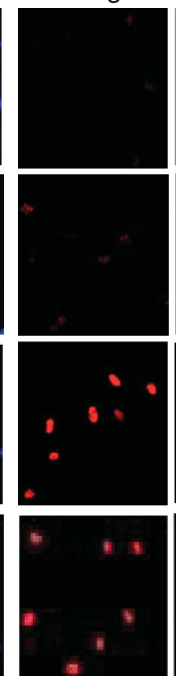

$\gamma \mathrm{H} 2 \mathrm{AX}$

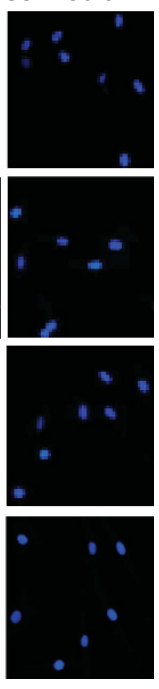

DAPI

\section{C}
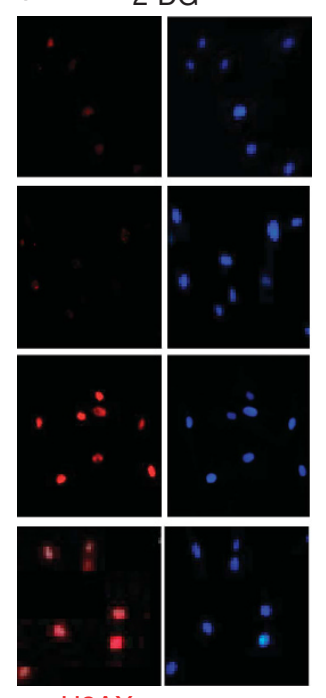

$\gamma \mathrm{H} 2 \mathrm{AX}$

DAPI
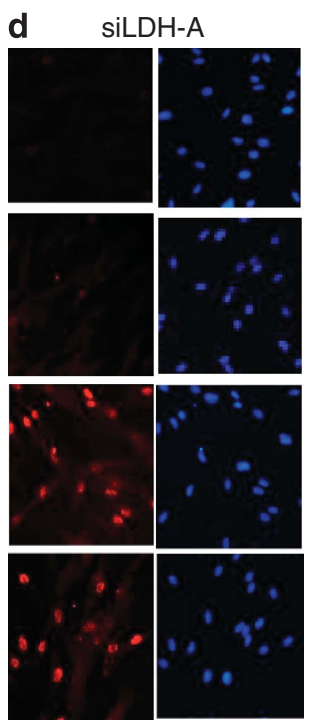

$\gamma \mathrm{H} 2 \mathrm{AX}$

\section{e $\quad$ SiG6PD}

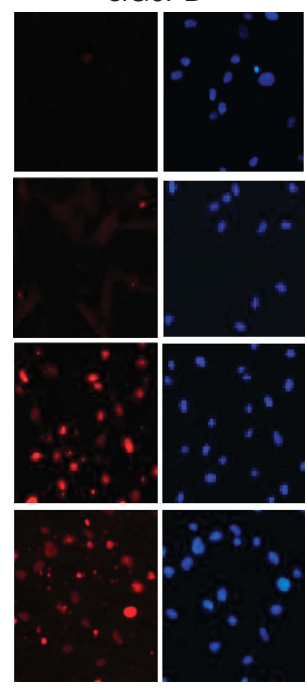

$\gamma \mathrm{H} 2 \mathrm{AX}$

DAPI
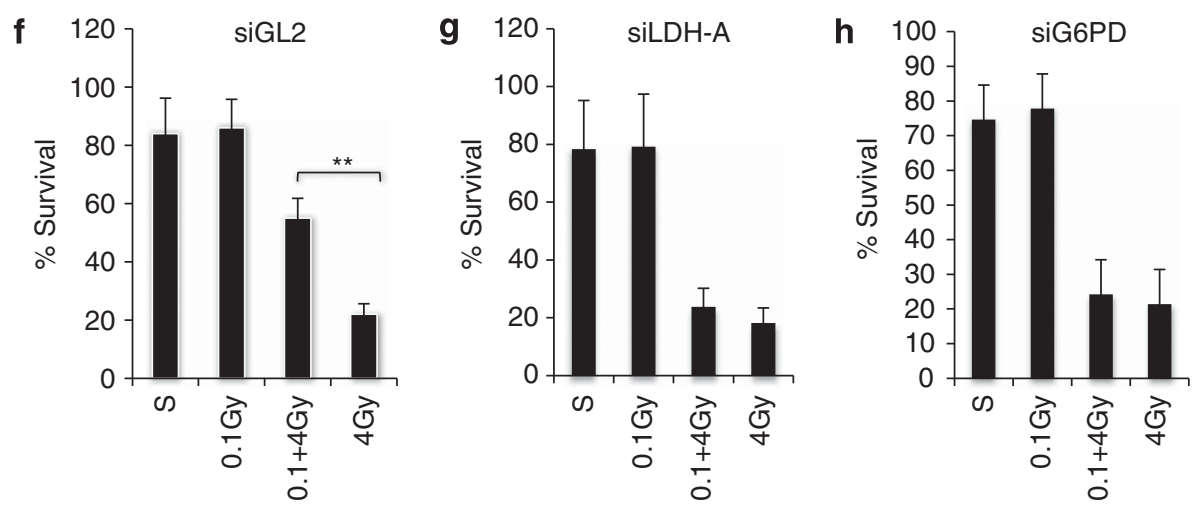

Figure 3 The glucose metabolism is necessary for low-dose IR-induced resistance. Human fibroblasts cultured in normal media (a) low glucose (2 mM) media (b) were pretreated with a dose of 0.1 Gy or sham treated, followed after $12 \mathrm{~h}$ by a 0 or 4.0 Gy treatment. The cells were fixed $1 \mathrm{~h}$ post 4 Gy treatment and co-immunostained with $\gamma \mathrm{H} 2 \mathrm{AX}$ (red) and DAPI (blue). (c) Fibroblasts were treated with 2-DG $(5 \mathrm{mM}) 2 \mathrm{~h}$ before $4 \mathrm{~Gy}$ treatment and subject to the treatment and analysis as in a. (d) Human fibroblasts were transfected with either siLDH $\alpha$ or siG6PD (e). The knockdown efficiency was determined by qRT-PCR analysis of mRNA levels (Supplementary Figure 2D). The cells were subjected to the treatment at $48 \mathrm{~h}$ post transfection, treated and analyzed as in a. The fibroblasts along with siControl (siGL2, a siRNA sequence targeting Luciferase gene) expressing cells $(\mathbf{f})$ were also subjected to colony survival assays $(\mathbf{g}$ and $\mathbf{h})$. The numbers are mean \pm S.D. from three independent experiments, ${ }^{*}<0.05,{ }^{* *}<0.01$

IR-induced GLUT-3 expression was restricted to the dose range of $0.05-0.175$ Gy (Figure $5 a$ ), doses that failed to induce p53 (Figure $5 b$ ). When the IR doses were beyond $0.2 \mathrm{~Gy}, \mathrm{p} 21$ expression was induced as a function of dose with little induction of GLUT-3 expression (Figures $5 a$ and $b$ ). Cell viability was not detectably affected by IR treatment within the low-dose range (Supplementary Figure 4A). The IR dosedependent reciprocal regulation of GLUT-3 and p21 was further confirmed by immunostaining (Figure $5 \mathrm{c}$ ). Together, the results indicate that IR-induced HIF1 $\alpha$ is specific to the dose range of $0.05-0.175$ Gy where there is little p53 activity. Once the IR dose increases beyond $0.2 \mathrm{~Gy}$, the activity of $\mathrm{p} 53$ become dominant with little activity of $\mathrm{HIF} 1 \alpha$ and glycolysis.

\section{Low-dose IR-induced metabolic changes underlie the} radioadaptive response in mouse tissues. To determine whether a similar low-dose radiation-induced metabolic response is observed in vivo, we extended our study to mice. Indeed, exposure of whole animals to $0.1 \mathrm{~Gy}$ radiation resulted in a robust induction of HIF1 $\alpha$ and GLUT-3 expression in the small intestine (Figure 6a), a tissue that is particularly susceptible to the damaging effects of radiation. ${ }^{33}$ Imaging of live animals with FDG-PET demonstrated a clear increase in glucose uptake specific to mice irradiated with $0.1 \mathrm{~Gy}$ or $0.1 \mathrm{~Gy}$ followed by $2 \mathrm{~Gy}$, but not in sham-treated or 2 Gy-treated mice (Figures $6 b$ and $c$ ). To determine whether these metabolic changes correlated with radiation sensitivity in mice, TUNEL assays were performed to assess cell death in the spleen and small intestine, two radiosensitive tissues. ${ }^{33}$ Treatment with 2 Gy irradiation induced massive apoptosis in the spleen and small intestine, which was markedly reduced by a proceeding dose of $0.1 \mathrm{~Gy}$ (Figures $6 \mathrm{~d}$ and e). Importantly, treatment of mice with 2-DG $(200 \mathrm{mg} / \mathrm{kg}$ ) largely abolished the $0.1 \mathrm{~Gy}$-induced resistance to high-dose irradiation in these tissues (Figures $6 \mathrm{~d}$ and e). These mouse studies provide in vivo evidence of low-dose irradiation-induced glucose flux associated with a considerable increase of radiation resistance in sensitive tissues. 


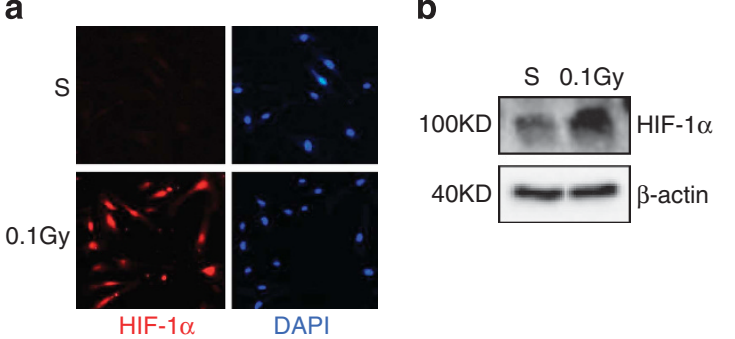

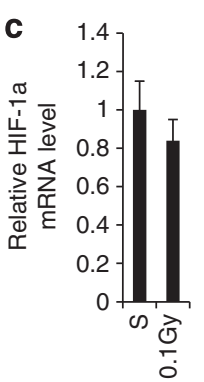

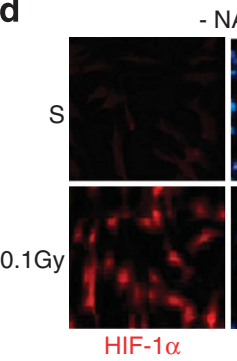

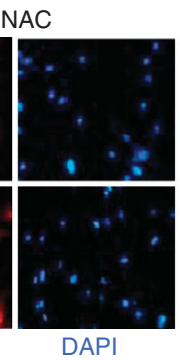

e

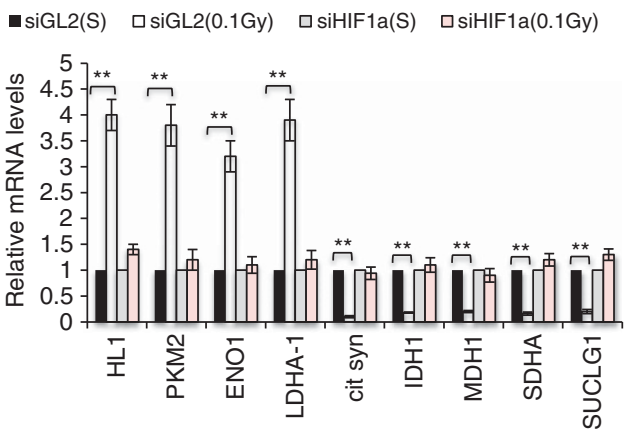

f

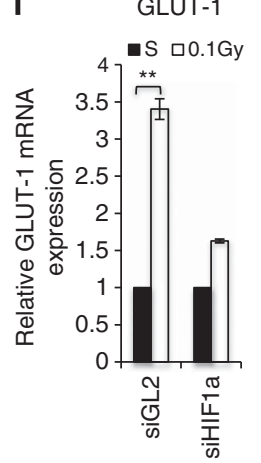

GLUT-3

g

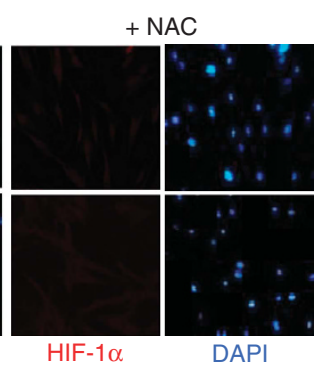

- $\triangle 0.1$ Gy
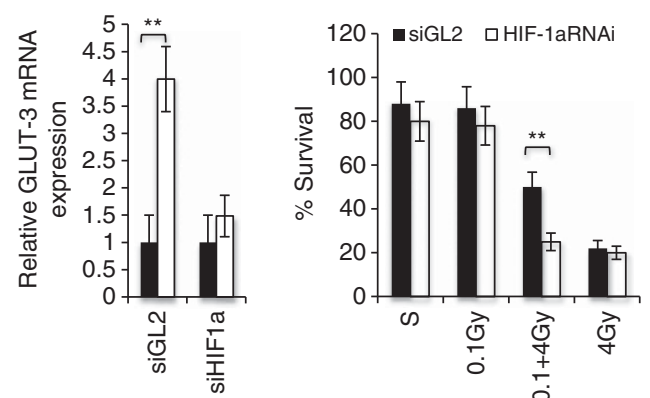

Figure 4 Low-dose IR-induced metabolic changes and radiation resistance are mediated by HIF- $1 \alpha$. Human fibroblasts were treated with a dose of $0.1 \mathrm{~Gy}$ or sham treated. The cells were harvested $12 \mathrm{~h}$ later and subjected to HIF-1 $\alpha$ (red) and DAPI (blue) immunostaining (a), western blot (b) or mRNA measurement by qRT-PCR (c). (d) Fibroblasts were treated with DMSO (-NAC) or $10 \mathrm{mM} \mathrm{NAC} \mathrm{(+NAC)} \mathrm{for} 1 \mathrm{~h}$ and then subjected to the treatment as in a. The cells were immunostained with HIF-1 $\alpha$. Fibroblasts were transfected with control (siGL2) or siHIF-1 $\alpha$. The HIF-1 $\alpha$ knockdown efficiency is shown in Supplementary Figure 4B. The cells were treated as in a and mRNAs were extracted for qRT-PCR for the expression of the indicated metabolic genes (e) or GLUT1 and 3 (f). The numbers are fold change of the mRNA levels in 0.1 Gy-treated cells relative to sham-treated cells as mean \pm S.D. from three independent experiments. (g) siGL2 or siHIF-1 $\alpha$ expressing cells were treated and subjected to the colony survival assay as described in Figure 3 f. The numbers are mean \pm S.D. from three independent experiments, ${ }^{*}<0.05,{ }^{* *}<0.01$

\section{Discussion}

Despite abundant data from epidemiological and animal studies supporting the radioadaptive response model, controversies surrounding the cellular effects of low-dose radiation persist. ${ }^{7,8}$ While many factors may influence the cellular response to low-dose radiation exposure, our studies demonstrated that the environmental oxygen concentration is an element of critical importance. Considering the fact that the principle mode of IR action is through induction of $\mathrm{ROS},{ }^{9}$ it is not surprising that the effects of low-dose IR, mediated by a moderate level of ROS, can be profoundly affected by oxygen concentration. Consistent with this notion is our finding that maintaining cell cultures at $5 \% \mathrm{O}_{2}$ was necessary to capture the radioadaptive response. Such a strong influence of oxygen concentration on ROS-mediated responses has important implications in cell-based stress response research, considering that studies have implicated ROS in various stress responses. ${ }^{11}$ Of note is the observation that low-dose IR-induced resistance seems not limited to irradiation, implicating an induction of a general cellular stress tolerance. ${ }^{6}$

Under physiological conditions, the majority of differentiated cells use primarily mitochondrial oxidative phosphorylation to fully catabolize glucose for energy production. ${ }^{20}$ Using a combined genetic, biochemical and metabolomics approaches, we demonstrate that low-dose radiation induces a metabolic switch from oxidative phosphorylation to aerobic glycolysis. This metabolic reprogramming is underscored by upregulation of genes encoding glucose transporters and enzymes of glycolysis and the oxidative PPP, concomitant with downregulated expression of TCA cycle enzymes. This metabolic change represents a previously unknown cellular response to low-dose radiation.

The low-dose radiation-induced glycolysis is reminiscent of the metabolic response of immune cells, which, upon activation, similarly switch the metabolic pathway from oxidative phosphorylation to aerobic glycolysis. ${ }^{34}$ This metabolic shift appears to be essential for immune cell proliferation and survival and for mounting an appropriate immune defense response. ${ }^{35}$ We show that the stimulation of glycolysis underpins low-dose radiation-induced radiation resistance, offering mechanistic insight into the radioadaptive response. The glycolytic pathway provides key intermediates for de novo synthesis of nucleotides, amino acids and lipids, and oxidative PPP produces NADPH to counter oxidative stress. ${ }^{20}$ Thus, by engaging glycolytic metabolism, cells may acquire fitness and stress tolerance. ${ }^{19,20}$ However, further studies are necessary to investigate how glycolysis renders cells resistant to IR-induced DNA damage.

This low-dose radiation-induced $\mathrm{HIF} 1 \alpha$ activation was in sharp contrast with the high-dose IR-induced p53 activation and $\mathrm{HIF} 1 \alpha$ inhibition. $\mathrm{HIF} 1 \alpha$ and $\mathrm{p} 53$ seem to have distinct roles in mediating the radiation dose-dependent metabolic response. The induction of $\mathrm{HIF} 1 \alpha$-mediated glycolysis is restricted to a low-dose range of radiation, which may have important implications in assessing the level of radiation exposure and its potential health risk. Our results support a dose-dependent 
a

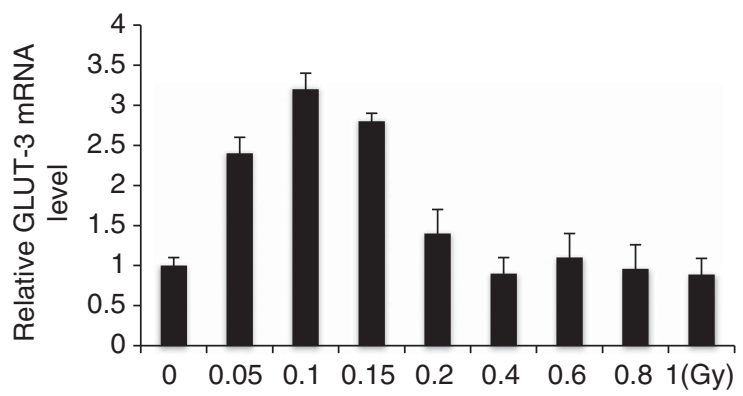

b

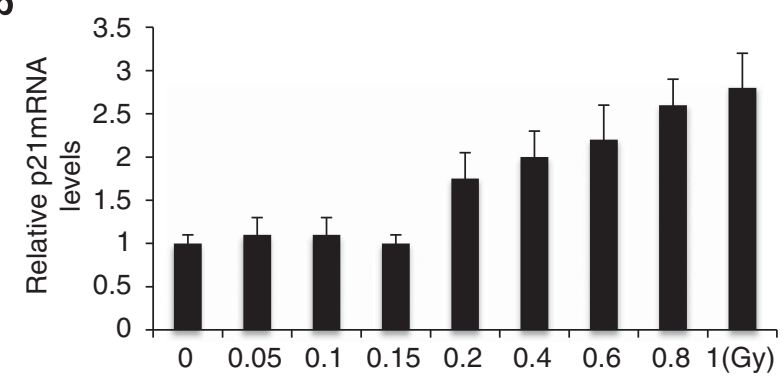

C

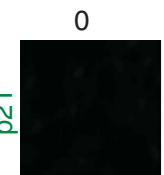

\begin{abstract}
0.025
\end{abstract}
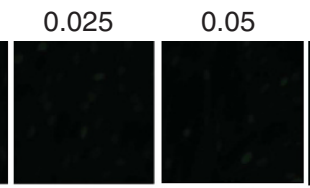

0.1

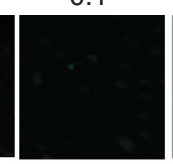

0.15

0.175

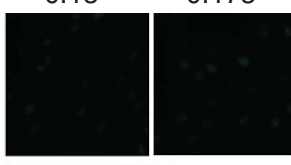

0.2

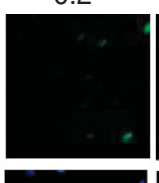

0.4
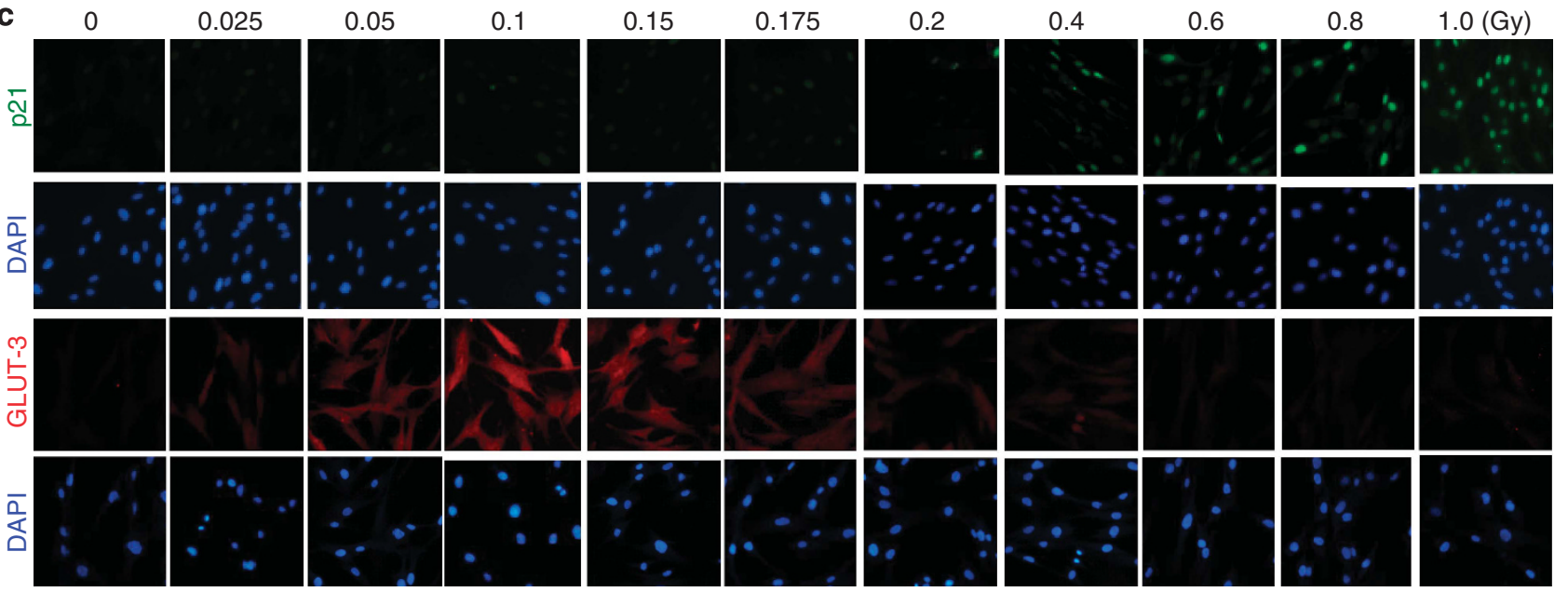

Figure 5 Distinct dose response of $p 53$ and HIF-1 $\alpha$ to irradiation. (a). Fibroblasts were irradiated with the indicated dose and harvested $12 \mathrm{~h}$ later. GLUT-3 mRNA was measured. (b) Fibroblasts were irradiated with the indicated dose and harvested $3 \mathrm{~h} \mathrm{later}$. Cellular mRNA was extracted for qRT-PCR for the expression of p21. The numbers are fold change of the mRNA levels in irradiated cells relative to sham-treated cells as mean \pm S.D. from three independent experiments. (c). Fibroblasts treated as in $\mathbf{a}$ or $\mathbf{b}$ were analyzed by immunostaining of p21 or GLUT-3 and counterstaining with DAPI

metabolic response to IR. When IR doses are below the threshold of causing detectable DNA damage ( $<0.2 \mathrm{~Gy}$ ) and thus little p53 activation, HIF1 $\alpha$ is induced resulting in induction of glycolysis and increased radiation resistance. When the radiation dose reaches levels eliciting DNA damage, p53 is activated and diminishes the activity of $\mathrm{HIF} 1 \alpha$ and glycolysis, leading to the induction of cell death. Our work challenges the LNT model of radiation exposure risk and provides a metabolic mechanism of radioadaptive response. The study supports a need for determining the $\mathrm{p} 53$ and $\mathrm{HIF} 1 \alpha$ activity as a potential reliable biological readout of radiation exposure in humans. The exquisite sensitivity of cellular metabolism to low doses of radiation could also serve as a valuable biomarker for estimating the health effects of low-level radiation exposure.

\begin{abstract}
Materials and Methods
Cell culture and irradiation treatment. All cell-based experiments were carried out under the physiological oxygen pressure $(5 \%)$. Human normal B-cell lymphocytes (GM03798, Coriell, Camden, NJ, USA) were maintained in RPMI-1640 supplemented with 10\% FBS, L-glutamine, HEPES buffer and sodium pyruvate. Human fibroblasts (GM08680, Coriell) were cultured in Dulbecco's modified Eagle's medium (DMEM) supplemented with 10\% FBS, L-glutamine and streptomycin. For irradiation, the Faxitron X-ray System (Faxitron X-Ray Corporation, Lincolnshire, IL, USA) was used. 0.1Gy was administered at a dose rate of $0.08 \mathrm{~Gy} / \mathrm{min}$. Two or $4 \mathrm{~Gy}$ was administered at a dose rate of $1 \mathrm{~Gy} / \mathrm{min}$.
\end{abstract}

Preparation of whole-cell lysates and western blotting. Westerns were performed as previously described ${ }^{36}$ with antibodies - Cell Signaling
Technology (Danvers, MA, USA): HK1, PKM2, Enol1, LDHA, G6PD; BD Biosciences (San Jose, CA, USA): HIF1 $\alpha$; Sigma-Aldrich (St. Louis, MO, USA): $\beta$-actin.

Immunofluorescence analysis. Immunofluorescence assays were performed as previously described. ${ }^{36}$ Antibodies were from Cell Signaling Technology: phospho-Ser139 H2AX, p21; Novus Biologicals (Littleton, CO, USA): HIF1 $\alpha$; Santa Cruz Biotechnology (Santa Cruz, CA, USA): DAPI, mouse Alexa Flour (AF) 488, rabbit AF 488, mouse AF 594 and Rabbit AF 594; Abcam (Cambridge, MA, USA): GLUT-1, GLUT-3. Nikon TE2000 (Melville, NY, USA) microscope and NIS elements software were used for imaging analysis of the cells.

siRNA-mediated gene knockdown. All siRNAs and primers were purchased from Sigma-Aldrich. Multiple sequences against each gene were used. siGL2, which targets the luciferase gene in pGL2 construct, was used as a control. siRNAs were reverse transfected at $25 \mathrm{nM}$ using Lipofectamine RNAiMAX (Invitrogen, Grand Island, NY, USA). The knockdown efficiency of each gene was determined with qRT-PCR and shown in Supplementary Figure 4.

Metabolic assays. Extracellular lactate was measured in cell culture media with a lactate assay kit (BioVision, Milpitas, CA, USA). Glucose levels were determined by the use of a glucose assay kit (BioVision) and glucose consumption was calculated as the difference of glucose concentrations between the original media and media from cell cultures. Glycolysis was determined by measuring ECAR using the XF Analyzer (Seahorse Bioscience, North Billerica, MA, USA). For the metabolic flux analysis, cells were washed once with glucose-free medium at $12 \mathrm{~h}$ post IR and then incubated in medium containing a $10 \mathrm{mM} \mathrm{1:1} \mathrm{mixture} \mathrm{of}$ $\mathrm{D}-\left[1,2-{ }^{13} \mathrm{C}\right]$-glucose and unlabeled $\mathrm{D}$-glucose for $15 \mathrm{~min}$. Metabolites were extracted on dry ice with $5 \mathrm{ml} 80 \%$ methanol. The extracts were dried under nitrogen and re-suspended in $80 \mu \mathrm{l}$ water for LC-MS analysis using the procedures previously described. ${ }^{27}$ Briefly, $1,2-\mathrm{C}^{13}$ glucose labeled samples were resuspended using $20 \mu \mathrm{l}$ HPLC grade water and $7 \mu \mathrm{l}$ were injected and analyzed 


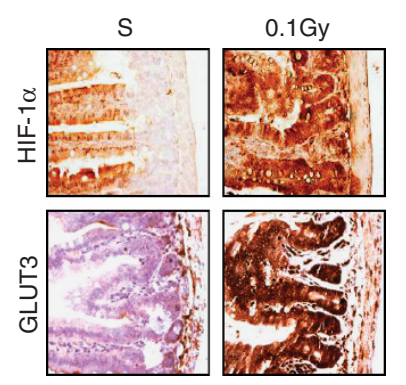

b

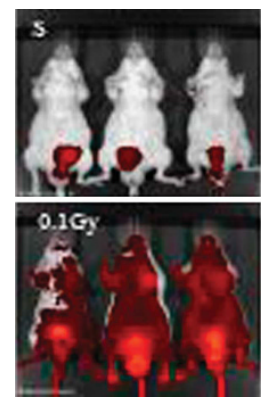

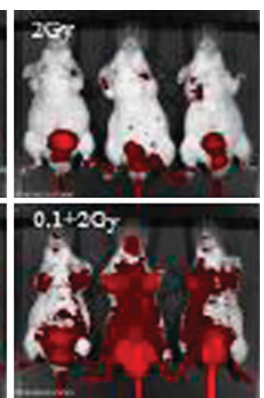

C

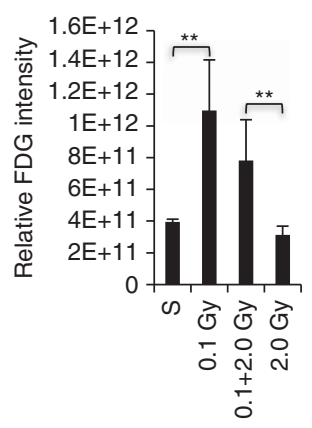

d

S

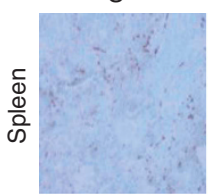

$0.1 \mathrm{G}$

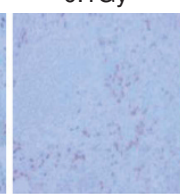

2DG
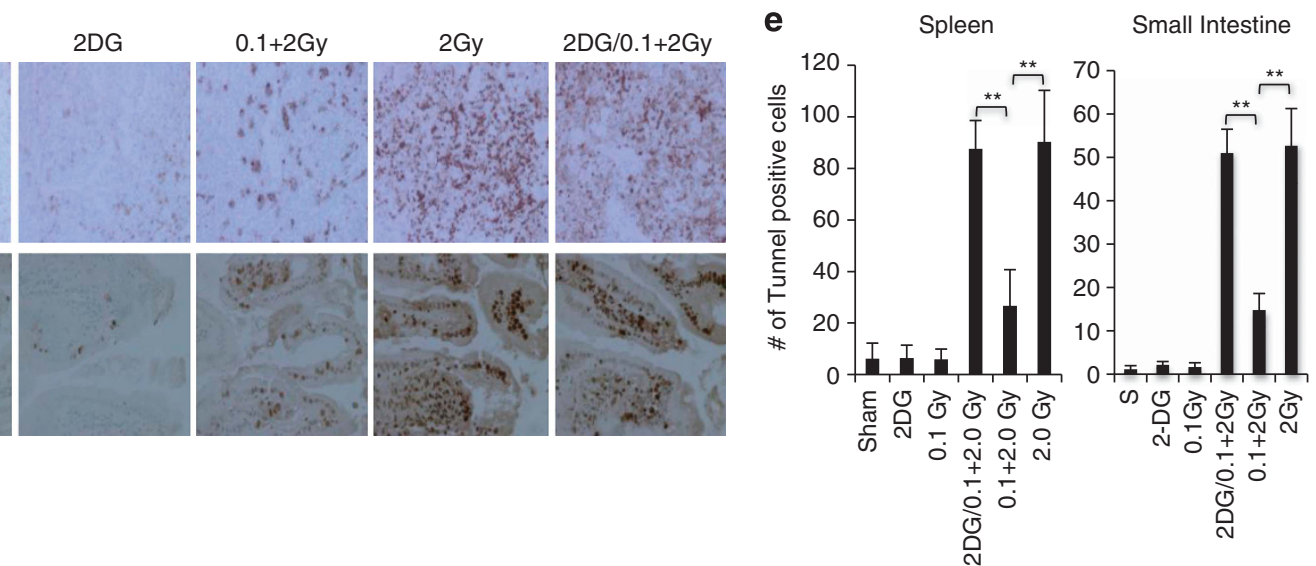

Figure 6 Low-dose irradiation induces glucose flux and radiation resistance in vivo. (a) BALB/C mice (4-6 weeks) were either sham-treated or 0.1 Gy irradiated. The expression of HIF $1 \alpha$ or GLUT-3 in the small intestine was examined $12 \mathrm{~h}$ post treatment by immunohistochemical staining. (b) Mice were treated with a $12-\mathrm{h}$ interval between a 0.1 Gy low-dose and $2 \mathrm{~Gy}$ high dose. Live animal imaging was performed $1 \mathrm{~h}$ after the 2 Gy irradiation using a procedure described in Materials and Methods to monitor the update of labeled glucose. The representative optical images are shown. (c) The quantitative data were acquired, analyzed using the manufacturer's Living Image 3.2 software and presented as means \pm S.D. (d). Mice (6 mice per group) were irradiated as described in $\mathbf{b}$ and treated with $100 \mu \mathrm{l}$ saline or 2-DG (200mg/kg body weight) for $2 \mathrm{~h}$ prior to the 2 Gy radiation treatment. The animals were harvested $12 \mathrm{~h}$ post-2 Gy irradiation. The spleen and small intestines were harvested and subjected to TUNEL assays. The representative images are shown. (e) The numbers of TUNEL positive cells were quantified using the J program and presented as mean \pm S.D. of six mice. $P<0.005$. For the quantification in the GI track, the TUNEL positive cells from 5 villas permouse were counted

with a hybrid 5500 QTRAP triple quadrupole mass spectrometer (AB/SCIEX) coupled to a Prominence UFLC HPLC system (Shimadzu, Columbia, MD, USA) via selected reaction monitoring (SRM). Seventy-five endogenous metabolites including unlabeled, 1-carbon and 2-carbon labeling were targeted using positive/ negative ion polarity switching (218 SRM transitions). Peak areas from the total ion current for each metabolite SRM transition were integrated using MultiQuant v2.0 software (Framingham, MA, USA) (AB/SCIEX).

Cell viability and FACs analysis. Cell viability and cell sorting analysis was performed as previously described. ${ }^{37}$

Animal study. All animal procedures were conducted in accordance with the Guidelines for the Care and Use of Laboratory Animals and were approved by the Institutional Animal Care and Use Committee at UTHSCSA. BALB/c mice 4-6 weeks old were purchased from Harlan Laboratories. Mice were housed under pathogen-free conditions and maintained on a $12 \mathrm{~h}$ light/12 $\mathrm{h}$ dark cycle, with food and water supplied ad libitum. Individual mice were treated with total body irradiation in a closed plastic box (of size $100 \mathrm{~mm}$ diameters $\times 50 \mathrm{~mm}$ height) with a small opening for aeration. The animals were injected intravenously through the tail vein with $100 \mu$ l of IR Dye $800 C W$ 2-DG (10 nmol) $1 \mathrm{~h}$ after the 2 Gy radiation treatment. For optical imaging, a caliper IVIS Spectrum system (Caliper, Alameda, CA, USA) was used to capture images for the experiments. The images were acquired with mice in supine position at $1 \mathrm{~h}$ and $4 \mathrm{~h}$ time points after the injection, using the epiillumination method at excitation wavelength of $745 \mathrm{~nm}$ and emission wavelength of $800 \mathrm{~nm}$. Camera settings were kept constant at $1 \mathrm{~s}$ exposure time, $4 \times 4$ binning, $12.6 \mathrm{~cm}$ field of view and $\mathrm{f} / \mathrm{stop}$ of $1 / 2$. The data were acquired and analyzed using Living Image 3.2 software (Waltham, MA, USA). For comparison purpose, all the images were thresholded on a minimum-maximum scale of 1.7e9-1.7e10 photons/ $\mathrm{s} / \mathrm{cm}^{2} /$ steradian. Photon intensities (photons/seconds) were calculated from each animal by placing a region of interest $(\mathrm{ROI})$ around the animal.

Histology/Immunohistochemistry. Histology and immunohistology were performed as previously described. ${ }^{36}$

Statistical analysis. Values are shown as mean \pm S.D. Comparison of mean values was evaluated by one-way ANOVA followed by $t$-test. A $P$-value less than 0.05 was considered significant.

\section{Conflict of Interest}

The authors declare no conflict of interest.

Acknowledgements. We would like to thank the UTHSCSA Small Animal Image Core, Suresh Prajapati for animal imaging studies, Min Yuan for help with mass spectrometry analyses and Drs. Hotamisligil \& Fu at HSPH for the XF Analyzer analysis. These studies were supported by the Morningside Foundation, the Department of Energy (DOE 110976 and 65089), NIH/NCI (2 R01CA085679, R01CA167814, R01CA125144, and P01CA120964).

\section{Author contributions}

ZY designed the experiments. RL, TX, HS, SX and MS contributed to cell-based studies. MY performed gene expression experiments. SG and CSH did in vivo work. JMA, IB-S, BDM and JBL planed and conducted metabolic analyses. Z-MY wrote and $\mathrm{BDM}$ and $\mathrm{JBL}$ edited the manuscript. 
1. Mobbs SF, Muirhead CR, Harrison JD. Risks from ionising radiation: an HPA viewpoint paper for Safegrounds. J Radiol Prot 2011; 31: 289-307.

2. Siegel JA, Stabin MG. Radar commentary: use of linear no-threshold hypothesis in radiation protection regulation in the United States. Health Phys 2010; 102: 90-99.

3. Mossman KS. Policy decision-making under scientific uncertainty: radiological risk assessment and the role of expert advisory groups. Health Phys 2009; 97: 101-106.

4. Vaiserman AM. Radiation hormesis: historical perspective and implications for low-dose cancer risk assessment. Dose Response 2010; 8: 172-191.

5. Calabrese EJ. The road to linearity, why linearity at low doses became the basis for carcinogen risk assessment. Arch Toxical 2009; 83: 203-225.

6. Mitchel RE. The dose window for radiation-induced protective adaptive responses. Dose Response 2010; 8: 192-208.

7. Morgan WF, Bair WJ. Issues in low-dose radiation biology: the controversy continues. A perspective. Radiat Res 2013; 79: 501-510.

8. Mullenders L, Atkinson M, Paretzke H, Sabatier I, Bouffler S. Assessing cancer risks of low-dose radiation. Nat Rev Cancer 2009; 9: 596-604.

9. Hall E, Giaccia AJ. Radiobiology for the Radiobiologist. Lippincott Williams \& Wilkins: Philadelphia, PA, USA, 2006.

10. Finkel T. Signal transduction by mitochondrial oxidants. JBC 2012; 287: 4434-4440.

11. Sena LA, Chandel NS. Physiological roles of mitochondrial reactive oxygen species. Mol Cell 2012; 48: 158-167.

12. Rhee SG, Bae YS, Lee SR, Kwon J. Hydrogen peroxide: a key messenger that modulates protein phosphorylation through cysteine oxidation. SCi STKE 2000; 53: pe1.

13. Tonks NK. Redox redux: revisiting PTPs and the control of cell signaling. Cell 2005; 121 : 667-670.

14. Goran JD, Simon MC. Hypoxia-inducible factors, central regulators of the tumor phenotype. Curr Opom Genet Dev 2007; 17: 71-77.

15. Semenza GL. Hypoxia-inducible factors in physiology and medicine. Cell 2012; 148: 399-408.

16. Van Uden P, Kenneth NS, Rocha S. Regulation of hypoxia-inducible factor- $1 \alpha$ by NF- $\kappa B$. Biochem J 2008; 412: 477-484.

17. Rois J, Guma M, Schachtrup C, Akassoglou K, Zinkernagel AS, Nizet V et al. NF- $\kappa B$ links innate immunity to the hypoxic response through transcriptional regulation of $\mathrm{HIF-1 \alpha}$ Nature 2008; 453: 807-811.

18. Pan Y, Mansfield KD, Bertozzi CC, Rudenko V, Chan DA, Giaccia AJ et al. Multiple factors affecting cellular redox status and energy metabolism modulate hypoxia-inducible factor prolyl hydroxylase activity in vivo and in vitro. Mol Cell Biol 2007; 27: 912-925.

19. Koppenol WH, Bounds PL, Dang CV. Otto Warburg's contributions to current concepts of cancer metabolism.. Nat Rev Cancer 2011; 11: 325-337.
20. Lunt SY, Vancer Heiden MG. Aerobic glycolysis: meeting the metabolic requirement of cell proliferation. Annu Rev Cell Dev Biol. 2011; 27: 441-464.

21. Chan SY, Zhang YY, Hemann C, Mahoney CE, Zweier JL, Loscalzo J. MicroRNA-210 controls mitochondrial metabolism during hypoxia by repressing the iron-sulfur cluster assembly proteins ISCU1/2. Cell Metab 2009; 10: 273-284.

22. Corn PG. Hypoxic regulation of miR-210: shrinking targets expand HIF-1s influence. Cancer Biol Ther 2008; 7: 265-267.

23. Kastan MB, Onyekwere O, Sidransky D, Vogelstein B, Craig RW. Participation of p53 protein in the cellular response to DNA damage. Cancer Res 1991; 51: 6304-6311.

24. Mole RH. The LD50 for uniform low LET irradiation of man. Br J Radiol 1984; 57: 355-369.

25. Ward JP. Oxygen sensors in context. Biochimica et Biophsica Acta 2008; 1777: 1-14.

26. Halestrap AP, Price NT. The proton-linked monocarboxylate transporter (MCT) family: structure, function and regulation. Biochem J 1999; 343: 281-299.

27. Yuan M, Breitkopf SB, Yang X, Asara JM. A positive/negative ion-switching, targeted mass spectrometry-based metabolomics platform for bodily fluids, cells, and fresh and fixed tissue. Nat Protoc 2012; 7: 872-881.

28. Ben-Sahra I, Howell JJ, Asara JM, Manning BD. Stimulation of de novo pyrimidine synthesis by growth signaling through mTOR and S6K1. Science 2013; 339: 1323-13287.

29. Fantin VR, St-Pierre J, Leder P. Attenuation of LDH-A expression uncovers a link between glycolysis, mitochondrial physiology, and tumor maintenance. Cancer Cell 2006; 9: 425-434.

30. Aylon Y, Oren M. New plays in the p53 theater. Curr Opin Genet Dev 2011; 21: 86-92.

31. Vousden KH, Prives C. Blinded by the light, the growing complexity of p53. Cell 2009; 37: 413-431.

32. Jackson JG, Post SM, Lozano G. Regulation of tissue- and stimulus-specific cell fate decisions by p53 in vivo. J Pathol 2011; 223: 127-136.

33. Gudkov AV, Komarova EA. The role of $p 53$ in determining sensitivity to radiotherapy. Nat Rev Cancer 2003; 3: 117-129.

34. Wang T, Marquardt C, Foker J. Aerobic glycolysis during lymphocyte-proliferation. Nature 1976; 261: 702-705.

35. Ben-Neriah Y, Karin M. Inflammation meets cancer, with NF-kappaB as the matchmaker. Nat Immunol 2011; 12: 715-723.

36. Huang $Y$, Zhang J, McHenry KT, Kim MM, Zeng W, Lopez-Pajares $V$ et al. Induction of cytoplasmic accumulation of p53: a mechanism for low levels of arsenic exposure to predispose cells for malignant transformation. Cancer Res 2008; 68 : 9131-9136.

37. Wiederschain D, Kawai H, Gu J, Shilatifard A, Yuan ZM. Molecular basis of p53 functional inactivation by the leukemic protein MLL-ELL. Mol Cell Biol 2003; 23: 4230-4246.

\section{Supplementary Information accompanies this paper on Cell Death and Differentiation website (http://www.nature.com/cdd)}

